\title{
CORRIGENDUM
}

to the paper

\section{ON A DUAL INTEGRAL EQUATION WITH A TRIGONOMETRIC KERNEL}

\section{by D. C. STOCKS}

Professor W. E. Williams (Surrey University) has recently pointed out to me that my paper is incorrect.

The step from equation (5) to equation (6) implies that $\phi$ is independent of $\lambda$, which the solution (11) shows is not the case. In view of this, equation (12) is not a solution to the original equations unless

$$
\int_{0}^{a} \phi(y) d y \int_{0}^{\infty} u \operatorname{cosech}^{2} u \sin u y \cos u z d u=0 \quad(0<z<a),
$$

with $\phi$ defined by (11).

I have not been able to show that this result is true, and so the dual integral equations solved are

$$
\begin{array}{ll}
\int_{0}^{\infty} \psi(u) \operatorname{coth} u z d u=h & (0<z<a), \\
\int_{0}^{\infty} \frac{\psi(u)}{u} \cos u z d u=0 & (a<z<\infty),
\end{array}
$$

and not those stated. In addition I have taken the opportunity to use a result due to Cooke (this Journal Vol 11, Part 1, Jan 1970) which is simpler than that of Parihar, quoted in my paper, to check the solution of equation (8) and this gives

$$
\phi(y)=\frac{2 h \tanh \gamma y}{\pi \cosh \gamma a\left[\tanh ^{2} \gamma a-\tanh ^{2} \gamma y\right]^{1 / 2}} .
$$

I regret any inconvenience this error may have caused. 